\title{
Managerial Mentoring Behaviour and Corporate Vitality in the Nigerian Aviation Sector
}

\author{
Christopher Akpotu, PhD \\ Department of Business Administration \\ Niger-Delta University Wilberforce Island \\ Amassoma, Nigeria \\ Rachel Konyefa, PhD \\ Department of Business Administration \\ Niger-Delta University Wilberforce Island \\ Amassoma, Nigeria.
}

\begin{abstract}
Despite substantial evidence on managerial roles in ensuring performance in work organizations, there is heightened need targeted at exploring and examining managerial behaviour that shapens and strengthen employee capacity that in turn stimulate the needed corporate vitality. This study therefore, examined the empirical link between managerial mentoring and corporate vitality in the Nigerian Hospitality subsector. The study used the questionnaire as the primary instrument for data generation from a sample of 226 respondents. The reliability of the survey instrument was ascertained relying on the Cronbach alpha of 0.78 and benchmarked with the Nunally alpha threshold of 0.7. the data were inferentially analyzed and the findings clearly indicates that a strong positive and significant relationship exist between managerial mentoring dimension of idea clarification empathizing, shared experience and attentiveness and corporate vitality measured with resourcefulness, responsiveness and innovativeness. this is as shown by $R=0.74$ and it is concluded that managerial mentoring relates with corporate vitality therefore it was recommended amongst others that managers should undertake deliberate and target mentoring initiative that will provide employees with much needed experience and skills that will strengthen the organization for goals.
\end{abstract}

Keywords: Mentoring, Managers, Attentiveness, Vitality, Responsiveness

\section{INTRODUCTION}

Organizations are contemporarily involved in crafting strategic actions and initiative aimed at achieving set goals and showing sustained competitive capability. These actions tend to amplify the need for corporate vitality that can be attained through a critical analysis of the knowledge assets and experience of work members. The reason for a qualitative workforce cannot be over emphasized against the backdrop of their strategic contributions towards corporate vitality. While this is acknowledged that the concept of vitality is relatively new in organization, it has remained a significant subject owing to the fact that it connotes the strength and capability to withstand environmental stressors that impedes capacity to survive (Nadum, 2011). Achieving vitality requires deliberate strategic and managerial character that support employees at all levels of work. In other words, aside instituting mechanism for coordination and control of all work actions, equipping them with the appropriate skills and providing support in the form of mentoring has been conceptually canvassed (Lankau \& Scandura, 2002; Chinowsky \& Carrillo, 2007). Some emphasis has been so far laid by some authorities Peripel \& Jones (2001), Orth, Wilkinson \& Benfari (2009), Vespa, Larry \& Billmore 
(2011) on employees misgiving on manager's inability to provide the desired guide and leading which has practically affected capacity to contribute strategically to work goals. There is heightened demand for employee playing strategic roles aside their traditional operational and on-the-shop-floor roles.

Achieving this work orientation for more horizontal workflows also reechoed managerial support through continuous and channeled interaction in the form of mentoring. The thinking here is that managerial experiences and capabilities can be so transferred and deposited knowingly on employee to undertake strategic responsibilities that ensures corporate vitality. While this is contentiously the case, the need for an empirical assertion is imperative for acceptability. In this study, the central objective is to establish through an empirical study, the relationship between managerial mentoring and corporate vitality. This again will help to introduce and validate the vitality construct which is the energy that is required to stay competitive in the complex and dynamic business environment.

\section{Managerial Mentoring}

\section{REVIEW OF LITERATURE}

The concept of mentoring has had huge theoretical exposition over time. It has enjoyed both longitudinal and on the spot conceptual focus that are also exponential in characterizing the concept (Cameron, 1978; Zachany, (2000); Kusilek \& Earnest 2001; Label and James, 2006, Kornor \& Pakora, 2007; Hunt \& Michusa, 2013). Interestingly, the multiplicity of focus notwithstanding, there is an apt definitional scope offered the concept that makes it conceptually and theoretical identifiable. Mentoring according to Ismail and Ariokasamy (2007) is a dyadic relationship between a more experienced member of an organization and a less experienced work member that provide the opportunity and a less experienced work member that provide the opportunity to share the professional and personal skills of the mentor with the mentee to enable him build capacity. Wanberg, Welsh \& Hezle (2013) aptly defined mentoring as a phenomenal guide, teaching offered by an experienced or advanced rank person (mentor) in order to develop a novice (mentee). This is aimed at developing the mentee in both professional and career advancement and at same time providing him with psycho-social reinforcement to undertake tasks. These positions provides a clear guide and amplifies the role of the mentor who undertakes mentoring as someone who activates the mentee and enable his capacity development sustainably to undertake challenging tasks and responsibilities that are value added. This objective of mentoring as described account for why Robinson (2013) viewed mentoring as a strategic organisational action aimed at building capacity of employee and providing the requisite skills that guarantee competitive advantage. While the definitions of mentoring offered in literature readily sign post the essence and functionality of the concept, its characterization is key to the understanding. Daniel (2004) argues that in mentoring, mentors are expected to be keen about the knowledge transfer modes that makes learning comprehensible for the mentee. What is required of mentors in their circumstance is that they ensure clarification of path to goals, amplify, and clear ideas that support mentee's contribution to work goals. Connor \& Pakora (2007), observed that achieving the objective of mentoring could be done through mentors psycho-emotional disposition and attachment to the plight of mentees. Simply put, mentors empathise with their mentees in order to have an understanding of their world which simply underscore their deficiencies that requires capacity building.

\section{Corporate Vitality}

The concept of corporate vitality has suffered from lack of distinctive labeling in corporate literature therefore has seemingly made it obscure in the organsitaion performance discourse. So far, the corporate vitality concept has a conceptual lens that prescribes its disposition to 
stemming the capacity of firms for competitiveness and achieving organizational goals. Corporate vitality is the activated organizational energy across all functions and resources that empower its drive towards goals (Matthews, 2009). Palmer (2011), has viewed corporate vitality as the totality of the functional operational capacity of the firms that is sustained for long-term survival. Fundamentally, organsiations are focused at crafting strategic alternatives that position them in their environment with a view to reaching desired goals and objectives. Corporate vitality provides the reiterating capacity and competences that channels actions at goals. Mavis (2011) discussed vitality of firms in relation with firm's ability to acquire resources that are needed for competitiveness. The author had characterized vitality of firms as been resourceful to the extent that it barely lacks the fundamental operational and administrative capabilities that promotes attainment of corporate goals. Narheke and Landtay (2011) views vitality of firms as being antecedental to some work place phenomenon and occurrences like responsiveness and innovativeness. The underlying assumption in their thought is that organisaiton has the potential to promptly and timely respond to stakeholders need areas while at same time ensuring processes that guarantee overall goal attainment. The potency of corporate vitality to initiate, prosecute and sustain action at goals is so far characterized by resourcefulness, responsiveness and innovative practices. Despite these functionalities that describes corporate vitality, a few studies have shown concern for what organizational efforts actions activates corporate vitality (Turban \& Dougherty, 1994; Chukwuigwe, 2002; Ottih, 2006). According to Jeruz (2014) the failure to identify the organsiational actions and behaviour that demonstrates vitality is likely to have resulted from conceptualization and operationalization of the construct. The measures of the construct adopted in this study are essentially tailored at addressing what behavioural practices amongst firm managers relate with corporate vitality.

\section{Managerial Mentoring and Corporate Vitality}

There is exponential growth on theoretical position regarding mentoring and workplace associated outcomes. Organizations are considering strategic options available for the development of the employee towards enhanced skills for competitiveness. Managerial mentoring across functions and levels of the organization expectedly provides the leverage needed for enhancing capabilities for the individual worker and the organization (Eby, Rhobes \& Allen, 2007; Boud, Rooney \& Solomon, 2009). The vast literature on mentoring notwithstanding, it has suffered from operational myopism that can easily describe it as a unidimensional construct and the implication is that it limits its acceptability and capacity to channel outcomes. Much of the mentoring literature has empirically linked it with employee performance. In some instances, there is what appears anecdotal evidence in relating the construct with team behaviour (Long, 2007; Ragins, 2009; Hunt \& Michael, 2013). In the works of Jambo and Maybridge (2011) the place of managerial mentoring as a behaviour modification and skill enhancement practice was emphasized. Infact, the correlational result from their study was empirically assertive which point to the fact that managerial mentoring does not fall short of the content required to ensure that employee knowledge content is improved upon to meet work goals. These positions notwithstanding, they have obscured the macro level functional implication of managerial mentoring as a strategic attempt at organizational goals. It has equally, to our mind, pushed to the periphery the principle of multiplier effect that emphasis one action leading to another. As firm strives towards competitive advantage, aggregate of strategic actions are expectedly conjectured. Their capacity to trigger micro level outcomes will undoubtedly facilitate macro level results. Against, this backdrop this study anchors its conceptualization on managerial mentoring capacity to relate with macro level outcome which in this instance is corporate vitality therefore it is hypothesized as follows:

Ho: Managerial mentoring does not relate significantly with corporate vitality 
Fig 1: Conceptual Framework on the Relationship between Managerial Mentoring (MMB) Behaviour and Corporate Vitality (CV).

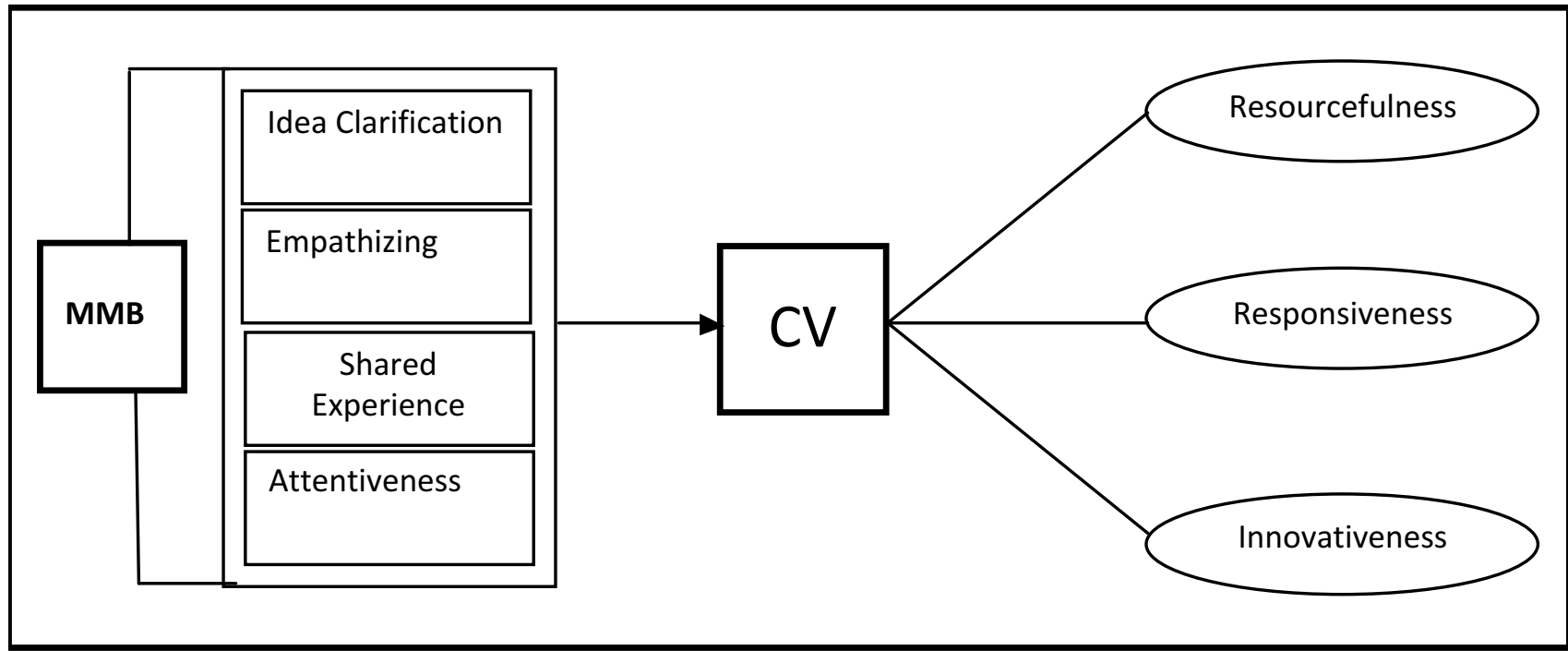

Source: Authors Desk

The conceptual framework as expressed show the dimensions and measures of the predictor and criterion variables examined in the study. The predictor variable, managerial mentoring behaviour is examined with its dimensions, idea clarification, empathizing, shared experiences and attentiveness (Balak and Shiney, 2011; Kranar and Barlor, 2012). the criterion variable, corporate vitality has responsiveness, resourcefulness and innovativeness Pitman (2014) as its measures.

\section{METHODOLOGY}

This study is conducted with a nomothetic research orientation. Therefore, quantitative perspectives were relied upon in obtaining and analyzing data. A structured survey instrument was used in generating data from the survey respondent sample. Since the unit of analysis was individual employee in the studied institution, a sample size of 164 employees was drawn. From the population of 286. The study sample subjects were selected using the proportionate stratified random sampling technique. The survey instrument was served using research assistants that were carefully appointed to enhance commitment of participant, ensures optimal return of the questionnaire and adherence to ethics in research (Metcalf, 2010)

\section{Measures}

The measurement scales used in this study are adapted from existing works. Mentoring behaviour scale was adapted from the Balak and Shiney (2011) 16 items scale which was validated in the works of Fajuyi and Meller (2013) with a co-efficient alpha of 0.77. Aside the undimensional scale of Balak and Shiney, it also considered the Kranar and Barlor (2012) 24 item multidimensional measurement scale for mentoring which was also confirmed reliable with a co-efficient alpha of 0.94 . The corporate vitality construct was measured relying on Pitman (2014) 11-item scale. The constructs were measured for reliability relying on Nunnally (1978) Cronbach alpha threshold of 0.7. The scales applicable were based on the 5 point Likerts scale which ranges from Strongly Agree 5 to Strongly Disagree 1. 
Table 1. Summary of Result of Reliability Analysis on Examined Constructs

\begin{tabular}{llll}
\hline S/No. & Dimensions/Measures & No of Items & Cronbach alpha $(\boldsymbol{\alpha})$ \\
\hline 1 & Idea clarification & 6 & 0.72 \\
2 & Empathizing & 5 & 0.78 \\
3 & Shared experiences & 5 & 0.82 \\
4 & Attentiveness & 5 & 0.74 \\
5 & Corporate vitality & 9 & 0.91 \\
\hline
\end{tabular}

\begin{tabular}{lll|lllllll}
\hline & Mean & Std & IC & EM & SE & AT & RF & RP & IN \\
\hline Idea Clarification & 4.411 & .795 & 1000 & & & & & & \\
Empathizing & 4.058 & 1.248 & $.026^{*}$ & 1000 & & & & \\
Shared Experiences & 3.641 & 1.411 & $.514^{*}$ & $427^{*}$ & 1000 & & & \\
Attentiveness & 4.112 & 1.268 & $.538^{*}$ & $.427^{*}$ & $032^{*}$ & 1000 & & \\
Resourcefulness & 3.470 & 1.328 & $.623^{*}$ & $.433^{*}$ & $511^{*}$ & $313^{* *}$ & 1.00 & & \\
Responsiveness & 3.705 & 1.317 & $.442^{*}$ & $.617^{*}$ & $326^{* *}$ & $583^{*}$ & $560^{*}$ & 1.00 & \\
Innovativeness & 3.581 & 1.325 & $.713^{*}$ & $.505^{* *}$ & $304^{* *}$ & $422^{* *}$ & $521^{* *}$ & $662^{*}$ & 1.00 \\
\hline
\end{tabular}

$* \mathrm{p}<0.05>, * * \mathrm{p}<0.01$ (2 tailed)

Multiple Regression Model Summary Showing Relationship between MMB and CV

\begin{tabular}{|c|c|c|c|c|c|c|}
\hline Model & $\mathrm{R}$ & $\mathrm{R}^{2}$ & $\mathrm{Ad}, \mathrm{R}^{2}$ & $\begin{array}{c}\text { Std Error } \\
\text { of Estimate }\end{array}$ & F-Charge & Sig \\
\hline 1 & .764 & .583 & .440 & .2296886 & 59.4 & 000 \\
\hline
\end{tabular}

(a) Predictor (Constant) idea clarification, empathizing, shared experiences, attentiveness

(b) Dependent Variable: Corporate Vitality

The result of the Pearson Statistic show correlation between the components of managerial mentoring behaviour operationalised and the measures of corporate vitality which includes resourcefulness, responsiveness and innovativeness. The regression analysis showing the coefficient of determination $\mathrm{R}^{2}$ indicates that $58 \%$ of the variability in the regressand is explained by the regressor. The remaining $42 \%$ of the variability is owned to an explained factors not contained in the model.

\section{DISCUSSION}

The findings of this study are interestingly illuminating and have expanded the understanding of managerial mentoring behaviour.. This is especially in its conceptual and objective focus on clarifying the character of managerial mentoring behaviour with the dimensions. The findings indicate a strong relationship between managerial mentoring behaviour and corporate vitality. By the measures of the dependent variable, the study findings support existing works of Dansels (2004). Managerial mentoring behaviour dimensions of attentiveness and idea clarification associate strongly with resourcefulness and responsiveness. Understandably, mentors provide guidance that channels outcome. Employees who have a clear understanding of organization vision and goals with the requisite skills are viewed as strategic resource. They are expected to provide the vigor that drives action aimed at desired work outcomes. The results of the study have substantiated Robinson (2013) findings on mentoring relationship with innovativeness while literature has amplified innovativeness as key to gaining competitive advantage; the study has provided the basis for emphasizing what workplace behaviour activates innovativeness. Managerial mentoring from this study associates with innovativeness, which is a measure of corporate vitality. Managers shared experiences in this regard are intellectually stimulating to the extent that they initiate and drive novel work process that strengthens capacity to achieve goals (Label \& James, 2006). Attentiveness behaviour in mentoring also shows assertive results in terms of association with corporate vitality measures. What this also imply is that employee (mentees) supports them as they 
strive to accomplish tasks. The findings support Kwemba and Runa (2010) and clearly initiates that irrespective of employee structural placement, they are interested in sharing ideas and attracting attention in a manner that facilitate and direct their effort at goals.

\section{CONCLUSIONS/ PRACTICAL IMPLICATIONS}

This study primarily investigated the empirical link between managerial mentoring behaviour and corporate vitality. The study was conducted relying on focused research questions that guided it with a view to explaining the phenomenon. From the data obtained and analyzed, there is a clear-cut demonstration of the strong relationship that exists between manager mentoring behaviour and corporate vitality. The study has successfully underscored the need for the managerial responsibility of reaching out to employees and helping them to acquire the needed competencies and psycho-social stability for goals and sustained survival of the organisation. This study has contributed to expanding existing knowledge level on managerial mentoring and workplace outcomes, represented as corporate vitality. In the light of the findings, managers in work organizations are to ensure relational climate at work that closely link them with other employees to acquire needed experience that strengthen their capacity to achieve desired work goals.

\section{SUGGESTION FOR FURTHER WORKS}

This study sets the platform for more works on managerial mentoring and work outcomes. It has provided the basis for exploring the empirical link between managerial mentoring and career outcome for the individual employee. In other words, a micro oriented analytical perspective is necessary in the mentoring discourse.

\section{References}

Balak, J and Shines, P. (2012). The Efficiency of Mentoring Programms in Service Firms Review of Literature, Journal of Organizational Behaviour, 6(11) 212-223.

Boud, D, Rooney, D. \& Solomon (2009). Talking Up Leaving at work: Cautionary Tales in Co-operating Everyday Learning International, Journal of Lifelong Education, Retrieved May 12009 From http://dx.doi.org/10.1080/0260113702799077.

Cameron P (1978). Mentoring phases and Outcome. Journal of Vocational Behaviour 31, 17-33

Chinowsky, P \& Carrillo, (2007) Knowledge Management to Learning Organisations Connection. Journal of Management in Engineering 23, 122-129

Chuwuigwe, C.M. (2002). Work and the Worker in Nigerian: A Case of Health Workers Sector.Out-Gal Journal of Management Sciences, 4(5), 81-89

Connor, M. \& Pakora, J. (2007). Coaching and Mentoring at Work: Developing Effective practice, Open University Press, Berkshine.

Daniels. M (2004). Mentoring: Link to the future, Reflections on Nursing Leadership, 30, 24-25

Eby, L.T, Rhodes, J.E. \& Allen, T.D (2007). Definition and Evolution of Mentoring. In T.D. Allen \& L.T Eby (Eds) The Backwell Handbook of Mentoring: A Multiple Perspective Approach (7-20) Malden. M.A: Backwell Pub.

Hunt, D.M. \& Micheal, C (2013). Mentorship: A Career Training and Development Tool, Academy of Managerment Review 8(3), 475-485

Ismail, M. \& Ariokasamy, L. (2007). Exploring Mentoring as a tool for Career Advancement of Academics in Private Higher Education Institution in Malaysis. Journal of International Social Research, 1(1), 135-148

Jambo, T.C and Maybridge, K.C (2011). Mentor-Self Esteem Fit and Relationship Satisfaction in Academic Mentoring. Journal of Behavioural Studies, 24(8), 312-327.

Jeruz, A.P (2014). Making the Firms Succeed: Strengthening and Managing Manufacturing firms. Journal of Business Management, 6(6), 142-154

Kranar, P. \& Balor, F.N (2012). Mentoring: Intra Functional Perspective, Journal of Organizational Behaviour, 22(8), 63-76 
Akpotu, C., \& Konyefa, R. (2018). Managerial Mentoring Behaviour and Corporate Vitality in the Nigerian Aviation Sector. Advances in Social Sciences Research Journal, 5(10) 44-50.

Kusilek, L.M \& Earnest, G.M (2001) Supporting Professional Growth through Mentoring an Coaching. Journal of Extension Services, 39, 1-9

Label, N. \& James, O.T (2006) Mentoring in Difficulties Reminiscing to Experiences. Journal of Organizational Behaviour 14(3), 214-226.

Lankau, M. \& Scandura, T. (2002). An Investigation of personal learning in mentoring relationships: Content, antecedents, and consequences. Academy of Management Journal, 779-790

Long. J. (2007). The dark side of mentoring. Australian Educational Research. 24, 115-123

Mathews, A.K. (2009). Unboundling Strategy and Facility Co-Opting for Long-term Competitiveness. Journal of Innovation Studies. 8(12), 162-176

Mavis, C.L (2011), Making the Enterprise Work; A Construes Strategic Search. Management Journal, 6(3), 82-91

Metcalfe, S.E. (2010). Educational Innovation: Collaborative Mentoring for future Nursing Leaders. Creative Nursing, 16, 167-170. Doc.10.1891/1073-4535.16.4.167

Nadum, K (2011). Mentoring for future Managers. What they know and know not. Journal of Educational Development 7(3), 48-62.

Nhareke, M \& Landtay, B.A (2011). Innovative Behaviour of Firms in Trubulent Environment: A Re-Examination of Merger and Acquisition Experiences in Developing Economies, Journal of Innovation Studies 11(4), 118-132.

Orth, C.D., Wilkinson, H.E. \& Benfari R.C. (2009). The Managers Role as Coach and Mentor. Organizational Dynamics 5(4) 66-74

Otti, L.O. (2006) General Management, Portharcourt: Pearl Pub

Palmer, M.O (2011). Reawakening and Strategic Remewal Motives, Journal of Organizational Competitiveness 12(4), 56-71

Peripel, M.A \&Jones, B. (2001). Workaholics and Overworker. Group and Organization Management, 26(3), 369393

Pitman, L.C (2014). Revitalizing Firm: A Story of Competitiveness. Journal of Strategic Management 7(8), 14-29

Ragins, B.R (2009). Barriers to Mentoring. The female managers dilemma. Human Relations 42(1), 50-56.

Robinson S. (2013)., Sustaining Mentorship for Student. Nurses Trevies, 109(16), 24-25

Turban, D \& Dougherty, T. (1994). Role of Protégé Personality in Receipt of Mentoring and Career Succcess. Academy of Management Journal, 688-702

Vespa, T.J, Larry B \& Billmore E.A (2011) Organized Mentoring: Examining Formal and Informal Relationship in High Tech Firm Journal of Organizational Studies 2(4), 94-104

Wanberg, C.R., E.T \& Hezlett, S.A (2003). Mentoring Research: A Review and Dynamic Process Model. Research in Personnel and Human Resource Management, 22, 39-124.

Wanberg. C.R., Welsh, E.T \& Hezle, S.A (2013) Mentoring Research: A Review of dynamic process model. Research in Personnel and Human Resource Management., 22(1). 39-124

Zachany .L. (2000). The Mentors guide: Facilitating effective learning relationships. San Francisco: Jossey-Bass 